\title{
PERMASALAHAN PENGERJAAN PONDASI DAN DINDING PADA PROYEK PERUMAHAN
}

\author{
Nina Nurdiani \\ Architecture Department, Faculty of Engineering, Binus University \\ Jl. K.H. Syahdan No. 9, Palmerah, Jakarta Barat 11480 \\ nnurdiani@binus.edu; nina.nurdiani@yahoo.co.id
}

\begin{abstract}
Good housing quality will make the age of building more longer, and occupants will be more comfortable to live in the house. Due to high of growth of housing projects and the need to finish quickly, developers often pay less attention to the quality of the building work. Many problems occurred in the work area during the construction of housing projects. It could hinder the work and affect the physical quality of buildings after the construction period. This study explores the issue of housing project development, focusing on foundation and wall consruction, as well as the solution. The study is conducted by field observations and literature review related foundation and wall consruction. The locations are taken from five housing projects in Jakarta built by private developers in 2008-2010. The results provide information that the issue on foundation and wall consruction is very important because it is associated with the strength and robustness of the building, as well as the convenience of staying after the construction finished. If the problems can be addressed and resolved early, the risk of decline in the quality of the building can be controlled, avoided or eliminated. Otherwise, it can lead to a decrease in housing quality prematurely.
\end{abstract}

Keywords: housing project, constuction, foundation, wall

\begin{abstract}
ABSTRAK
Kualitas perumahan yang baik akan membuat usia bangunan lebih lama, dan penghuni akan lebih nyaman untuk tinggal di rumah. Dikarenakan oleh tingginya pertumbuhan proyek perumahan dan kebutuhan untuk segera menyelesaikannya, pengembang kurang memperhatikan kualitas pengerjaan bangunan. Banyak permasalahan yang terjadi di lapangan selama pembangunan proyek perumahan. Ini bisa menghambat pengerjaan di lapangan dan dapat mempengaruhi kualitas fisik bangunan setelah masa konstruksi. Penelitian ini membahas masalah pengerjaan proyek pembangunan perumahan, khususnya masalah pengerjaan pondasi dan pengerjaan dinding, dan bagaimana solusinya. Penelitian ini dilakukan dengan observasi lapangan dan kajian literatur yang berhubungan dengan pengerjaan pondasi dan pengerjaan dinding. Lokasi penelitian dilakukan di lima lokasi proyek perumahan di Jakarta yang dibangun oleh pengembang swasta tahun 20082010. Hasil dari penelitian ini memberikan pengetahuan bahwa masalah pengerjaan pondasi dan pengerjaan dinding sangat penting karena terkait dengan kekuatan dan ketahanan bangunan, serta kenyamanan tinggal setelah konstruksi. Jika masalah tersebut tidak segera ditangani dapat menyebabkan penurunan kualitas perumahan prematur. Namun, jika masalah dapat diatasi dan diselesaikan lebih awal, risiko penurunan kualitas bangunan dapat dikendalikan, dihindari atau dihilangkan.
\end{abstract}

Kata kunci: proyek perumahan, pengerjaan pondasi, pengerjaan dinding 


\section{PENDAHULUAN}

Pembangunan proyek perumahan oleh developer di berbagai kawasan dan daerah menunjukkan bahwa kebutuhan perumahan menjadi kebutuhan dasar kedua bagi masyarakat. Tingginya kebutuhan perumahan mendorong pengembang untuk membangun proyek perumahan di pinggiran kota atau di pusat kota. Pertumbuhan yang tinggi dalam proyek-proyek perumahan terus menuntut kualitas perumahan yang lebih baik. Kualitas perumahan yang baik akan membuat usia bangunan lebih lama, dan penghuni akan lebih nyaman untuk tinggal di rumah.

Kegiatan pembangunan proyek rumah tinggal dimulai dari pengerjaan pondasi sampai dengan pengerjaan finishing. Tingginya pertumbuhan proyek perumahan dan mereka semua membutuhkan segera selesai menyebabkan pengembang kurang memperhatikan kualitas pengerjaan bangunan. Banyak permasalahan yang terjadi di lapangan selama pembangunan proyek perumahan. Ini bisa menghambat pengerjaan di lapangan dan dapat mempengaruhi kualitas fisik bangunan setelah selesai masa pembangunan.

Untuk dapat mengurangi atau mengendalikan permasalahan yang terjadi pada pengerjaan proyek pembangunan rumah tinggal perlu dilakukan studi. Pengerjaan pondasi dan pengerjaan dinding dipelajari lebih dulu karena pengerjaan tahap awal pembangunan rumah tinggal umumnya adalah pengerjaan pondasi dan pengerjaan dinding. Tentunya permasalahan tersebut harus dapat diidentifikasi dan dicarikan solusinya, agar kualitas bangunan tetap baik dan di masa datang permasalahan tersebut dapat dihindari atau dihilangkan. Permasalahan yang akan dijawab melalui studi ini adalah: (1) apa saja permasalahan yang sering terjadi terkait pengerjaan pondasi dan pengerjaan dinding pada proyek perumahan?; (2) bagaimana solusi terkait permasalahan pada pengerjaan pondasi dan pengerjaan dinding?

Tujuan studi adalah untuk mengidentifikasi dan memahami permasalahan apa saja yang terjadi di lapangan terkait pengerjaan pondasi dan pengerjaan dinding pada proyek perumahan, dan bagaimana solusinya. Manfaat studi ini adalah untuk menambah pengetahuan terkait pemahaman konstruksi bangunan rumah tinggal dan pelaksanaan pengerjaan konstruksi bangunan di lapangan, khususnya pengetahuan terkait permasalahan pengerjaan pondasi dan dinding, serta solusinya.

\section{METODE}

Untuk dapat menjawab permasalahan yang terjadi di lapangan terkait pengerjaan pondasi dan pengerjaan dinding pada proyek perumahan, serta bagaimana solusinya, dilakukan studi dengan pendekatan deskriptif pada beberapa proyek pembangunan perumahan oleh pengembang (developer) swasta di Jakarta. Unit analisisnya yaitu pengerjaan pondasi dan pengerjaan dinding pada proyek rumah tinggal yang sedang berjalan yang disurvei antara tahun $2008-2012$.

Metode pengambilan data primer dilakukan melalui metode survei pengamatan (observasi) lapangan di lima lokasi proyek rumah tinggal di perumahan yang dibangun pengembang swasta di Jakarta yaitu di Perumahan Casa Goya, rumah tinggal di Komplek Mega Kebon Jeruk, rumah tinggal di Perumahan Royal Residence, rumah tinggal di Perumahan Green Garden, rumah tinggal di Perumahan Green Mansion. Pengumpulan data sekunder dilakukan melalui studi literatur terkait pengerjaan konstruksi bangunan rumah tinggal khususnya pengerjaan pondasi dan pengerjaan dinding. Analisis data dilakukan secara deskriptif dengan membandingkan dan melihat persamaan serta perbedaan pelaksanaan pengerjaan pondasi dan pengerjaan dinding pada proyek pembangunan rumah tinggal serta memetakan solusi mengatasi permasalahan tersebut. 


\section{HASIL DAN PEMBAHASAN}

\section{Pengerjaan Pondasi}

Pondasi adalah bagian bangunan yang berfungsi menyalurkan beban bangunan ke tanah. Perhitungan ukuran pondasi dan pembangunan pondasi yang tepat akan menghindarkan penurunan gedung yang tidak merata dan menghindari robohnya bangunan. Karena penurunan gedung yang tidak merata dapat mengakibatkan retak pada dinding, dinding yang tidak sejajar anting, atau pintu dan jendela menjadi tidak bisa dibuka.

Pada bangunan rumah tinggal, pondasi yang umumnya digunakan pondasi lajur dari batu kali atau pondasi setempat (telapak). Pondasi batu kali dibuat dari pecahan batu kali yang cukup besar. Harus diperhatikan agar celah-celah antara batu kali selalu berselang-seling dan diisi dengan adukan. Lebar pondasi dibuat sekitar $5 \mathrm{~cm}$ lebih tebal dari dinding pada kedua sisi pondasi (Gambar 1). Pondasi setempat (telapak) dibuat dari beton bertulang. Biasanya digunakan pada kolom-kolom utama untuk menyalurkan beban ke tanah pada bangunan rumah tinggal dua lantai.
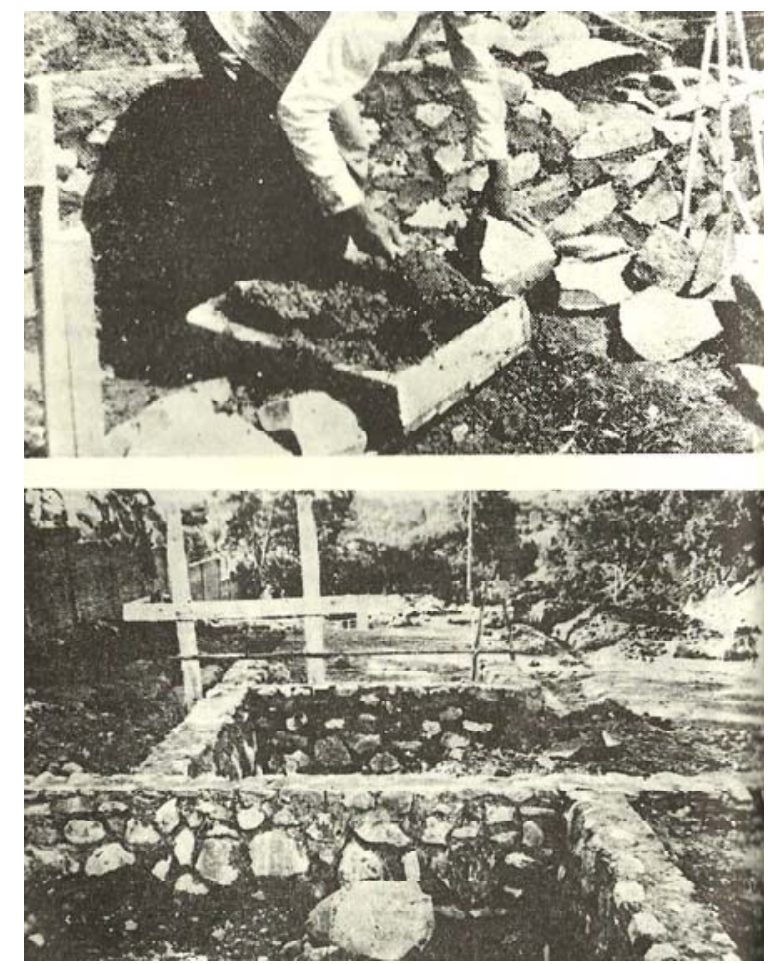

Sumber: Heinz Frick

Gambar 1. Cara pemasangan pondasi batu kali di proyek pembangunan rumah tinggal.

\section{Pengerjaan Dinding}

\section{Konstruksi Dinding Bata Merah}

Bata merah adalah bahan bangunan dari tanah liat (lempung) untuk dinding yang dibuat sebagai hasil "home industry" atau perusahaan batu bata. Ciri-ciri bata merah yang baik yaitu: permukaannya kasar, warna merah seragam (merata), bunyinya nyaring, dan tidak mudah hancur atau 
patah. Ukuran standar bata merah yaitu: (1) panjang $240 \mathrm{~mm}$, lebar $115 \mathrm{~mm}$, tebal $52 \mathrm{~mm}$; (2) panjang $230 \mathrm{~mm}$, lebar $110 \mathrm{~mm}$, tebal $50 \mathrm{~mm}$; (3) panjang $240 \mathrm{~mm}$, lebar $120 \mathrm{~mm}$, tebal $70 \mathrm{~mm}$.

\section{Konstruksi Dinding Batako}

Batako adalah bahan bangunan dari campuran tras dan kapur, atau semen-pasir-dan air. Ukuran batako lebih besar dari bata merah, sehingga penggunaan batako untuk dinding dapat lebih hemat dari bata merah, karena jumlah batako yang digunakan lebih sedikit untuk ukuran per $\mathrm{m}^{2}$ luas dinding. Apabila kualitas batako baik dan pemasangaannya baik, kadang dinding batako tidak perlu diplester lagi, cukup dicat agar nyaman, bersih dan rapi.

Ukuran standar batako yaitu: (1) panjang $40 \mathrm{~cm}$, lebar $20 \mathrm{~cm}$, tinggi $20 \mathrm{~cm}$, berlubang, untuk dinding luar; (2) panjang $40 \mathrm{~cm}$, lebar $20 \mathrm{~cm}$, tinggi $20 \mathrm{~cm}$, berlubang, batu khusus sebagai penutup pada sudut-sudut dan pertemuan-pertemuan dinding; (3) panjang $40 \mathrm{~cm}$, lebar $10 \mathrm{~cm}$, tinggi $20 \mathrm{~cm}$, berlubang, untuk dinding pengisi dengan tebal $10 \mathrm{~cm}$; (4) panjang $40 \mathrm{~cm}$, lebar $10 \mathrm{~cm}$, tinggi $20 \mathrm{~cm}$, berlubang, batu khusus sebagai penutup pada dinding pengisi; (5) panjang $40 \mathrm{~cm}$, lebar $10 \mathrm{~cm}$, tinggi $20 \mathrm{~cm}$, tidak berlubang, batu khusus untuk dinding pengisi dan/atau pemikul sebagai hubunganhubungan sudut dan pertemuan; (6) panjang $40 \mathrm{~cm}$, lebar $8 \mathrm{~cm}$, tinggi $20 \mathrm{~cm}$, tidak berlubang, batu khusus untuk dinding pengisi.

\section{Pemasangan Konstruksi Dinding Bata Merah}

Pemasangan bata merah harus membentuk kesatuan sekaligus menerima beban dengan baik. Sehingga siar-siar vertikal (adukan antara pasangan bata merah) pemasangannya harus saling bersilang (Gambar 2). Siar vertikal umumnya berjarak $1 \mathrm{~cm}$ dan siar horizontal setebal 1,5cm.

Cara pemasangan batu bata merah yang benar adalah sebagai berikut. Sebelum pemasangan bata merah perlu dibasahi lebih dahulu untuk menghindari retak pasangan bata karena bata merah bersifat porous. Penyusunan bata tiap hari juga tidak boleh lebih dari 1,5 m tingginya agar tidak susut ke arah vertikal karena pasangan bata belum kering. Setelah lapisan pertama pada lantai atau pondasi dipasang, maka papan mistar yang menentukan tinggi lapisan masing-masing, sehingga dapat diatur seragam. Lapisan kedua dan lapisan berikutnya pada bata merah masing-masing diletakkan adukan pada dinding yang sudah didirikan untuk siar horizontal, dan pada bata merah yang akan dipasang pada sisi sebagai siar vertikal. Bata merah dipasang mengikuti tali yang telah dipasang menurut papan mistar sampai bata merah duduk rapat dan tepat. Dengan sendok adukan, adukan yang berlebihan dan keluar dari sisi-sisi bata merah dipotong, agar rata dan rapi. Jika dinding terlalu panjang untuk menggunakan sebuah waterpas. Atau jika tidak dapat melihat dari satu ujung dinding ke ujung lainnya, kita dapat memakai selang plastik yang disi dengan air.

\section{Pemasangan Konstruksi Dinding Batako}

Pemasangan batako sebenarnya tidak jauh berbeda dengan pemasangan bata merah. Cara pemasangan batako adalah sebagai berikut. Sebelum pemasangan batako tidak perlu dibasahi terlebih dahulu, tidak boleh direndam air. Untuk pemotongan batako dipergunakan palu dan tatah (untuk membuat goresan pada batako), sesudahnya dipatahkan pada batu yang cukup lancip. Sebelum pemasangan, batako disusun dan diatur lebih dahulu di tepi atau di atas pondasi (rolag), agar tidak ada kelebihan atau kekurangan batu. Pada letak pintu-pintu juga diberi tanda. Kemudian dimulai dengan pemasangan batu batako pertama dari sudut-sudut bangunan dan berakhir di tengah-tengah. Pada sudut-sudut bangunan masing-masing diberi papan mistar dan tali pelurus untuk menentukan tinggi lapisan batako. Pemasangan batako terakhir selalu di tengah-tengah. Untuk memperkuat dinding batako juga digunakan rangka pengkaku yang terdiri dari kolom atau balok beton bertulang yang dicor di dalam lubang-lubang batako. Kolom beton ini selalu dipasang di sudut-sudut, pertemuan dan persilangan dinding batako. 

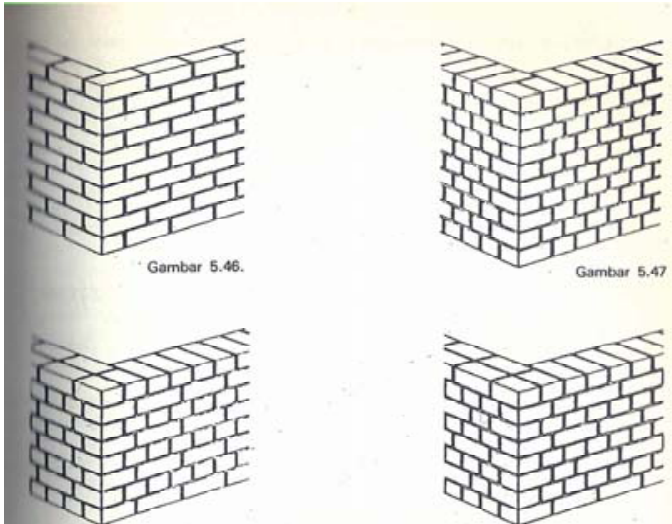

Gambar 5.48 .
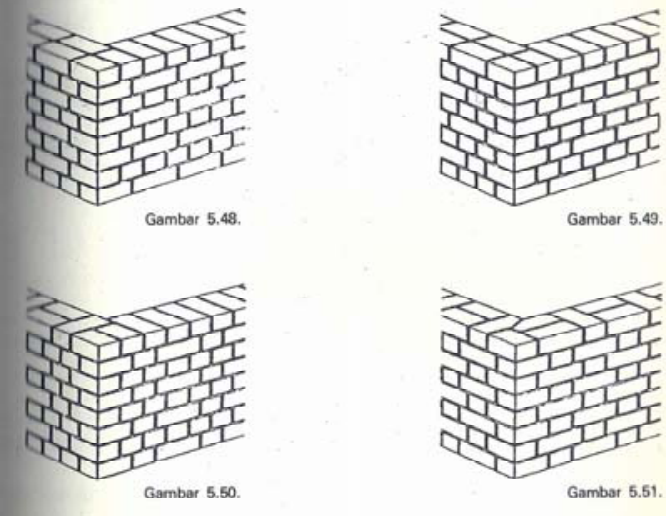

Gambar 5.49

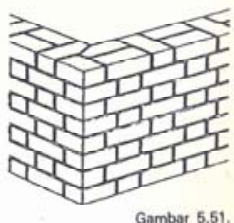

Gambar 5.51.
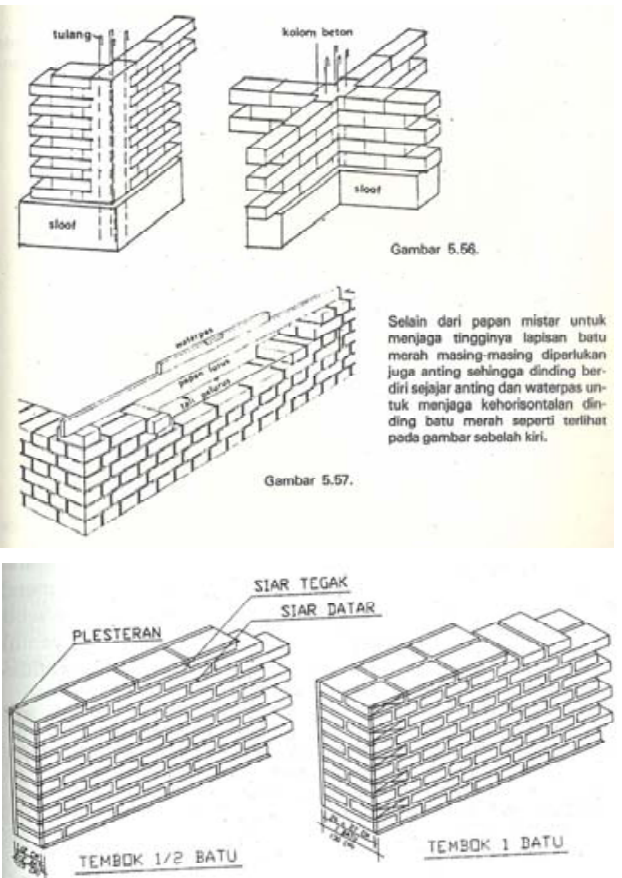

Sumber: Heinz Frick

Gambar 2. Konstruksi dinding bata merah untuk proyek pembangunan rumah tinggal (5.46 s/d 5.57).

\section{Permasalahan pada Pengerjaan Pondasi}

Pengerjaan pondasi pada proyek rumah tinggal di perumahan perlu diperhatikan dengan baik karena kekuatan dan kekokohan pondasi bangunan akan diperoleh apabila mulai pengerjaan awal pondasi dan pemasangan material bangunan untuk pondasi dibangun dengan benar.

Permasalahan umum pada pengerjaan pondasi yang terjadi di lapangan dari hasil survei di lima lokasi perumahan antara lain karena faktor cuaca (40\%), pelaksanaan pengerjaan pondasi tidak sesuai standar prosedur (20\%), dan ketrampilan tukang yang masih terbatas/kurang mahir (40\%). Ketiga permasalahan ini paling umum terjadi dalam pembangunan proyek rumah tinggal (Gambar 3).

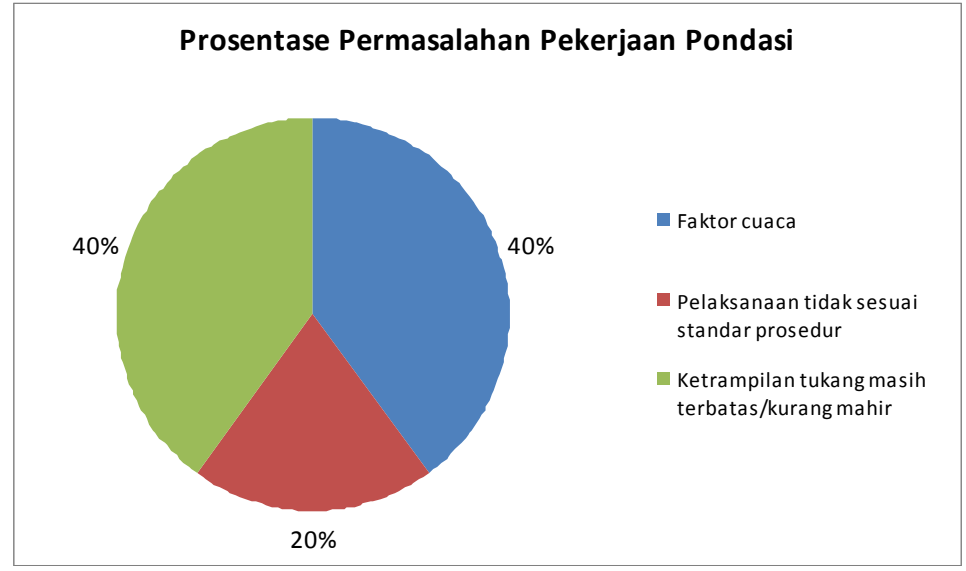

Sumber: Hasil Analisis Peneliti (2012)

Gambar 3. Diagram prosentase permasalahan pengerjaan pondasi pada proyek rumah tinggal di Jakarta. 
Permasalahan pengerjaan dinding yang paling umum terjadi dari hasil survei di lima lokasi perumahan antara lain pelaksanaan pengerjaan dinding tidak sesuai standar prosedur pemasangan dinding (10\%), permukaan dinding yang tidak rata (10\%), Retak rambut pada dinding (40\%), plesteran dinding keropos dan berguguran (10\%), pemasangan nat antar keramik tidak rata (10\%), dan keramik dinding terlepas sesaat setelah pemasangan (10\%). Keenam permasalahan di atas paling umum terjadi pada pelaksanaan pengerjaan dinding pada proyek rumah tinggal (Gambar 4).

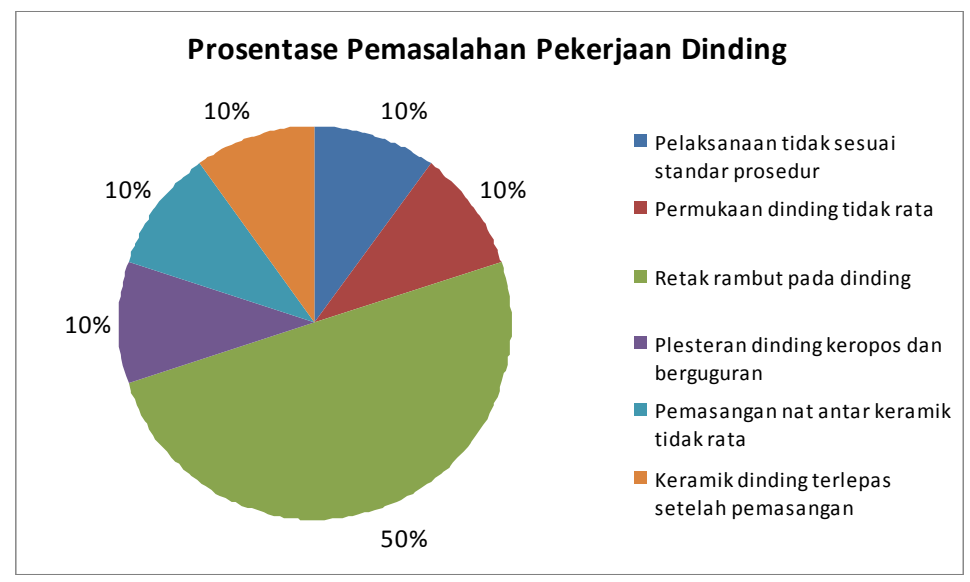

Sumber: Hasil Analisis Peneliti (2012)

Gambar 4. Diagram prosentase permasalahan pengerjaan dinding pada proyek rumah tinggal di Jakarta.

Permasalahan pengerjaan pondasi terkait faktor cuaca di lapangan antara lain hujan yang mengakibatkan galian pondasi longsor, jadwal kerja tidak tepat waktu, dan lain sebagainya. Permasalahan pelaksanaan pengerjaan pondasi di lapangan yang tidak sesuai standar prosedur pengerjaan pondasi antara lain terjadi pembelokan pondasi tiang pancang, dan lain sebagainya. Permasalahan pengerjaan pondasi terkait kurangnya tingkat profesional tukang/pekerja lapangan antara lain salah penulisan pada bowplank yang mengakibatkan salah galian pondasi, dan lain sebagainya.

Solusi faktor cuaca di lapangan antara lain dilakukan dengan pemakaian terpal waktu hujan dan bentuk galian pondasi trapesium untuk menghindari galian pondasi longsor. Solusi pelaksanaan pengerjaan pondasi di lapangan tidak sesuai standar prosedur pengerjaan pondasi adalah pengawasan pelaksanaan pengerjaan pondasi yang perlu ditingkatkan. Solusi kurangnya tingkat profesional tukang atau pekerja lapangan antara lain tukang diawasi dan diarahkan, lebih teliti dalam menulis tanda pada bowplank dan gunakan cat semprot untuk tulisan penanda.

\section{Permasalahan pada Pengerjaan Dinding}

Permasalahan pengerjaan dinding umumnya terkait para tukang/pekerja tidak mengikuti standar prosedur pelaksanaan pengerjaan dinding antara lain tukang malas menggunakan benang sebagai lot horisontal sehingga pasangan bata pada dinding tidak rata, dan lain sebagainya. Permasalahan pengerjaan dinding terkait permukaan dinding tidak rata umumnya disebabkan karena pemasangan bata tidak teliti sehingga ketebalan pasangan bata pada dinding berbeda.

Permasalahan pengerjaan dinding yaitu retak rambut pada dinding umumnya disebabkan karena kualitas dan ukuran bata berbeda, penggunaan bata -bata yang pecah, proses pengacian bertahap, kualitas pasir kurang baik, kondisi dinding terlalu kering, dan lain sebagainya. Permasalahan plesteran dinding keropos dan berguguran umumnya disebabkan karena proses pemlesteran kurang 
baik, kurang semen pada adukan plesteran, dan lain sebagainya. Permasalahan pemasangan nat antar keramik pada dinding tidak rata umumnya disebabkan karena kurangnya adukan untuk pasang keramik dinding, sehingga permukaan dinding tidak rata, dan lain sebagainya. Permasalahan keramik dinding terlepas sesaat setelah pemasangan umumnya disebabkan karena plesteran dinding kurang dikasari. Solusi untuk pengerjaan dinding yang tidak sesuai/tidak mengikuti standar prosedur antara lain dengan mngawasi dan mengarahkan tukang dan menggunakan benang pelurus sebagai lot horisontal. Permukaan dinding tidak rata dapat ditangani dengan cara pembobokan permukaan dinding apabila perbedaan ketebalan permukaan dinding besar. Selain itu, apabila perbedaan ketebalan permukaan dinding tipis dapat diratakan dengan plesteran.

Solusi untuk retak rambut pada dinding yaitu dengan cara menyiramkan air ke bata sebelum diplester. Sebelum pengacian, plesteran bata disiram air agar jenuh air. Setelah diplester, lakukan penyiraman kembali untuk memperlambat proses pengeringan plesteran sehingga resiko retak rambut pada dinding dapat dikurangi. selanjutnya bagian yang retak didempul (Gambar 5), dihaluskan dengan ampelas, lalu dicat kembali (Gambar 6). Bagian dinding siku diberi kawat ayam terlebih dahulu sebelum diplester kembali. Solusi untuk plesteran dinding yang keropos dan berguguran antara lain dengan melakukan plester ulang dan sebelumnya memberikan kawat ayam pada bagian yang terkelupas agar hasil plesteran lebih kuat. Sedangkan untuk pemasangan nat antar keramik yang tidak rata dapat diatasi dengan membongkar keramik dan memberi adukan secukupnya, serta menggunakan bantuan benang sebagai lot vertikal dan lot horisontal. Untuk keramik dinding yang terlepas setelah pemasangan, solusinya adalah dengan membuat kasar kembali permukaan plesteran dinding dengan pahat/palu sehingga adukan melekat erat pada dinding.

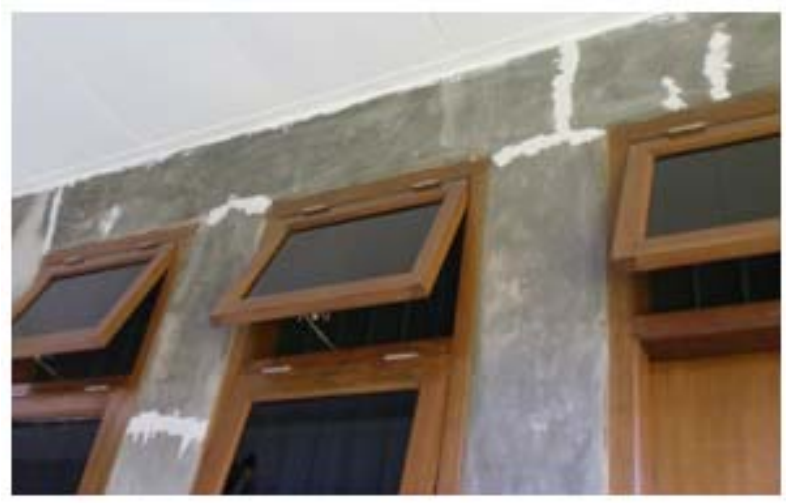

Sumber: Hasil Survei Peneliti (2012)

Gambar 5. Retak rambut pada dinding yang sudah didempul.

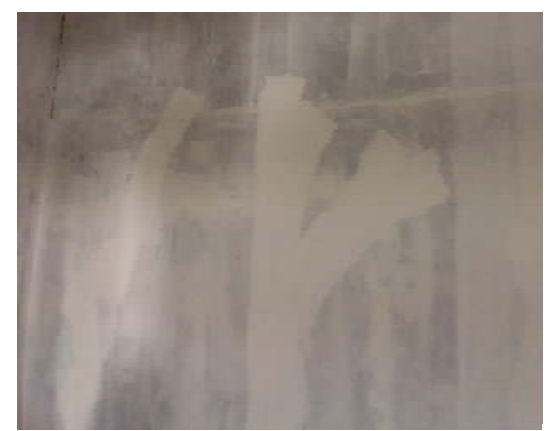

Sumber: Hasil Survei Peneliti (2012)

Gambar 6. Dempulan retak rambut yang sudah diampas dan diaci, serta siap dicat kembali. 
Permasalahan umum pada pengerjaan pondasi dan pengerjaan dinding terjadi di lapangan umumnya disebabkan karena ketrampilan tukang yang masih kurang dan pelaksanaan pengerjaan lapangan oleh tukang yang tidak sesuai prosedur standar. Faktor cuaca dan kualitas material bangunan adalah penyebab lainnya dari permasalahan pengerjaan pondasi dan pengerjaan dinding.

Permasalahan pengerjaan pondasi dan pengerjaan dinding harus segera diatasi dan ditangani agar kualitas bangunan tidak cepat menurun dan usia bangunan cukup panjang. Kualitas bangunan yang baik dan usia bangunan yang cukup lama akan membuat penghuni nyaman dan betah tinggal di rumah dan biaya pemeliharaan dan perbaikan dapat dihemat. Upaya lain adalah dengan melakukan pengawasan pengerjaan lapangan yang intensif sehingga tukang melakukan pengerjaannya dengan baik. Jika masalah dapat diatasi dan diselesaikan lebih awal, risiko penurunan kualitas bangunan dapat dikendalikan, dihindari atau dihilangkan.

\section{PENUTUP}

Hasil studi mengenai permasalahan pengerjaan pondasi dan pengerjaan dinding memberikan pengetahuan bahwa masalah pengerjaan pondasi dan pengerjaan dinding sangat penting karena terkait dengan kekuatan dan ketahanan bangunan, dan dalam hubungannya dengan kenyamanan tinggal penghuni setelah masa konstruksi selesai.

Permasalahan umum pada pengerjaan pondasi dan pengerjaan dinding yang umum terjadi adalah karena ketrampilan tukang yang masih kurang dan pelaksanaan pengerjaan lapangan yang tidak sesuai prosedur standar. Penyebab lain dari permasalahan pada pengerjaan pondasi dan pengerjaan dinding adalah faktor cuaca dan kualitas material bangunan.

Upaya pengawasan pengerjaan lapangan yang intensif, penanganan masalah pengerjaan pondasi dan pengerjaan dinding yang segera dilakukan akan membantu usia bangunan cukup panjang. Jika masalah di lapangan dapat diatasi dan diselesaikan lebih awal, risiko penurunan kualitas bangunan juga dapat dikendalikan, dihindari atau dihilangkan. Kualitas bangunan yang baik dan usia bangunan yang cukup panjang akan membuat penghuni nyaman dan betah tinggal di rumah dan biaya pemeliharaan serta perbaikan bangunan dapat dihemat.

\section{DAFTAR PUSTAKA}

Allen, Edward (2005). Dasar-dasar Konstruksi Bangunan (Jilid 1). Jakarta: Penerbit Erlangga.

Ferdhian, M., Yustika, N., Martha, Y. (2008). Laporan Kerja Praktek Rumah Tinggal di Perumahan Casa Goya - Jakarta. Jakarta: Jurusan Arsitektur, Universitas Bina Nusantara.

Frick, Heinz (1991). Ilmu Konstruksi Bangunan 1. Yogyakarta: Penerbit Kanisius.

Julistiono H. (2005). Menggambar Struktur Bangunan. Jakarta: Grasindo.

Lou, Ken (2003). Re-Thinking Building Construction. Singapore: Asiamedia Publishing.

Nugroho, N., Wibowo, Satrio J., Dwicahyasani, D. (2008). Laporan Kerja Praktek Rumah Tinggal di Komplek Mega Kebon Jeruk Blok E No. 5 - Jakarta Barat. Jakarta: Jurusan Arsitektur, Universitas Bina Nusantara. 
Ronald, Stephanus (2009). Laporan Kerja Praktek Rumah Tinggal di Royal Residence - Jakarta Timur. Jakarta: Jurusan Arsitektur, Universitas Bina Nusantara.

Sophia, L., Saba, Deby Y., Hanifati, Duhita A. (2010). Laporan Kerja Praktek Rumah Tinggal di Perumahan Casa Goya - Jakarta Barat. Jakarta: Jurusan Arsitektur, Universitas Bina Nusantara.

Sumitro, A. dan Fernandina, W. (2009). Laporan Kerja Praktek Rumah Tinggal di Perumahan Green Mansion - Jakarta. Jakarta: Jurusan Arsitektur, Universitas Bina Nusantara. 